\title{
Valorization of biomass waste from yellow horn (Xanthoceras sorbifolia) through the preparation of porous carbon for supercapacitors
}

Fenfang Luo, Yves Iradukunda, Kaiqiang Yi, Yawen Hu, Xin Li, Guoying Wang, Gaofeng Shi*

School of Petrochemical Engineering, Lanzhou University of Technology, Lan gong ping Road, Lanzhou, Gansu, China

*E-mail: $1538601086 @$ qq.com

doi: $10.20964 / 2021.03 .34$

Received: 9 November 2020 / Accepted: 18 December 2020 / Published: 31 January 2021

Hot trends have always been the successful production of green energies and the promotion of the added value of agricultural goods. In this research, we introduced a new type of porous carbon material which, after extracting oil from the Yellowhorn for high-performance supercapacitors, uses $\mathrm{H}_{3} \mathrm{PO}_{4}$ as an activator and is made from biomass waste. To date, experiments on nitrogen adsorption/desorption indicate that $\mathrm{H}_{3} \mathrm{PO}_{4}$-activated bio-carbon has strong pore-forming potential, while the basic surface area is $1530.18 \mathrm{~m}^{2} / \mathrm{g}$. The average pore volume of is $0.97 \mathrm{~cm}^{3} / \mathrm{g}$. In contrast, carbon content electrochemical efficiency demonstrates a high specific capacitance of $246.5 \mathrm{~F} / \mathrm{g}$ in $6 \mathrm{M} \mathrm{KOH}$ aqueous solution at $1 \mathrm{~A} / \mathrm{g}$. However, a high energy density of $34.24 \mathrm{Wh} / \mathrm{kg}$ is also provided by the proposed symmetrical supercapacitor. at a density of $500 \mathrm{~W} / \mathrm{kg}$ of power. The above results thus suggest that the by-product of biomass waste is an outstanding substitute material for high-performance supercapacitor preparation.

Keywords: Yellowhorn; bio-carbon; supercapacitors; electrochemical performance

\section{$\underline{\text { FULL TEXT }}$}

(C) 2021 The Authors. Published by ESG (www.electrochemsci.org). This article is an open-access article distributed under the terms and conditions of the Creative Commons Attribution license (http://creativecommons.org/licenses/by/4.0/). 